\title{
Antimicrobial Agents That Inhibit the Outer Membrane Assembly Machines of Gram-Negative Bacteria
}

\author{
Umji Choi and Chang-Ro Lee* \\ Department of Bioscience and Bioinformatics, Myongji University, Yongin 17058, Republic of Korea
}

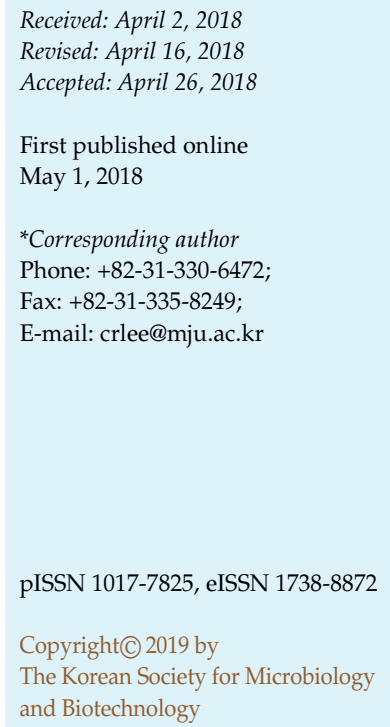

Gram-negative pathogens, such as Klebsiella pneumoniae, Pseudomonas aeruginosa, and Acinetobacter baumannii, pose a serious threat to public health worldwide, due to high rates of antibiotic resistance and the lack of development of novel antimicrobial agents targeting Gram-negative bacteria. The outer membrane (OM) of Gram-negative bacteria is a unique architecture that acts as a potent permeability barrier against toxic molecules, such as antibiotics. The OM is composed of phospholipids, lipopolysaccharide (LPS), outer membrane $\beta$-barrel proteins (OMP), and lipoproteins. These components are synthesized in the cytoplasm or in the inner membrane, and are then selectively transported to the OM by the specific transport machines, including the Lol, BAM, and Lpt pathways. In this review, we summarize recent studies on the assembly systems of OM components and analyze studies for the development of inhibitors that target these systems. These analyses show that OM assembly machines have the potential to be a novel attractive drug target of Gram-negative bacteria.

Keywords: Antimicrobial agents, outer membrane assembly machine, lipoprotein, lipopolysaccharide, outer membrane $\beta$-barrel protein, phospholipid

\section{Introduction}

The outer membrane (OM) of Gram-negative bacteria is a unique architecture with an asymmetric bilayer, which consists of phospholipids in the inner leaflet and lipopolysaccharide (LPS) in the outer leaflet [1]. In addition to phospholipids and LPS, there are a variety of bilayeranchored lipoproteins and outer membrane $\beta$-barrel proteins (OMPs) in the OM [2]. Lipoproteins play an important role in several essential and non-essential functions, including the linkage between the $\mathrm{OM}$ and peptidoglycan [3], peptidoglycan synthesis [4, 5], pili and flagella assembly $[6,7]$, and protein and polysaccharide secretion [8, 9]. Porin, a major OMP of the OM, forms specific and non-specific channels that regulate the transport of hydrophilic molecules across the OM [10, 11].

The OM functions as an additional barrier that inhibits the transport of toxic molecules such as antimicrobial compounds. Therefore, compounds with a molecular weight (MW) of more than 600 Da cannot pass through the Gramnegative bacteria cell envelope. For example, vancomycin and daptomycin which have a MW of more than 1,400 Da are not able to penetrate the OM of Gram-negative bacteria [12]. This feature of Gram-negative bacteria is one of the major obstacles in novel antibiotic discovery targeting clinically important Gram-negative pathogens, such as Klebsiella pneumoniae, Pseudomonas aeruginosa, and Acinetobacter baumannii $[13,14]$. Therefore, screening for inhibitors that block OM biogenesis is a good strategy for the development of novel antimicrobial agents. In this review, we will summarize recent findings about the transport and assembly of $\mathrm{OM}$ components and analyze trends in the development of antimicrobial compounds inhibiting OM assembly.

\section{OM Assembly Machines}

\section{Lipoproteins and OMPs}

Lipoproteins containing a so-called lipobox, a consensus sequence [LVI][ASTVI][GAS]C, are translocated across the inner membrane (IM) by the Sec or Tat system $[15,16]$. The maturation of lipoprotein precursors occurs on the outer leaflet of the IM by sequential functions of phosphatidylglycerol/ 
A

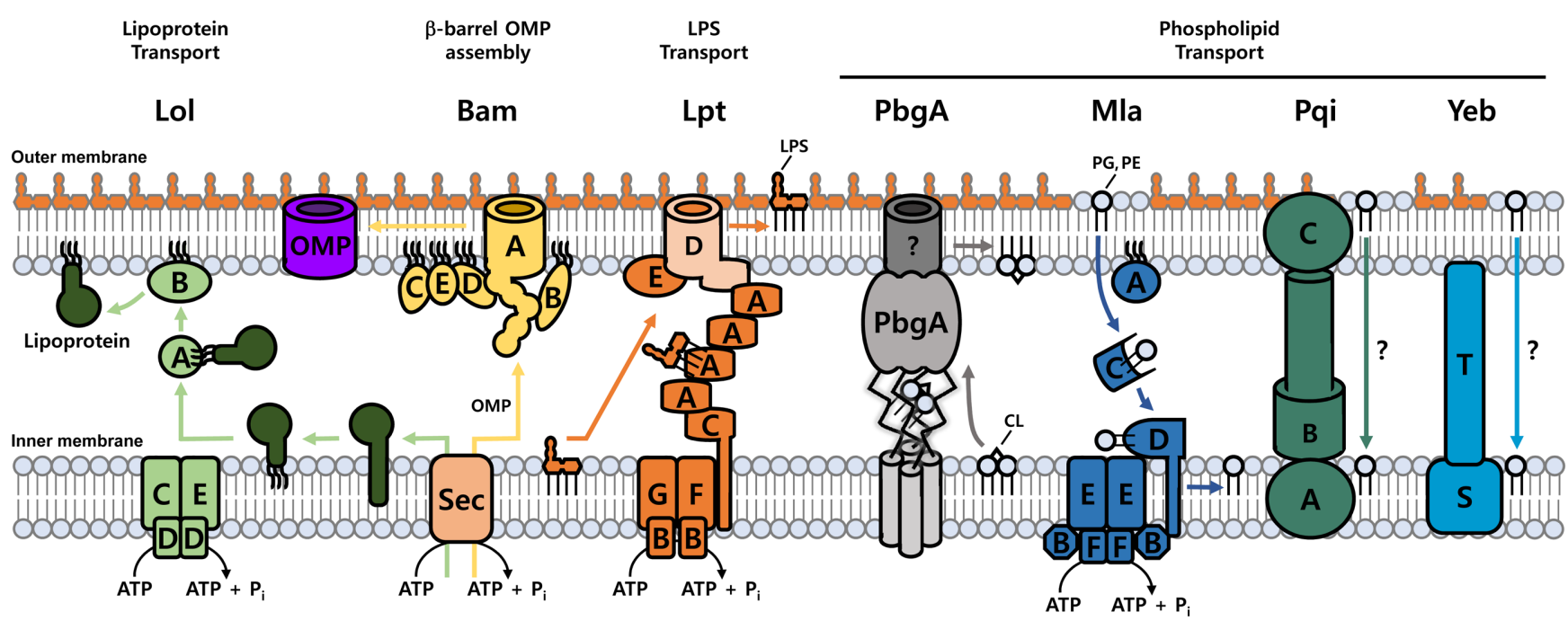

Fig. 1. The outer membrane assembly machines in E. coli.

(A) The Lol pathway. After IM insertion of lipoprotein precursors by the Sec system, lipoprotein precursors are processed to lipoproteins. The lipoproteins extracted by the LolCD $\mathrm{E}_{2}$ complex are transferred to LolB in the OM through the periplasmic protein LolA. Lipoproteins of LolB are released in the OM. (B) The Bam pathway. OMPs secreted by the Sec system are inserted into the OM by the Bam assembly machine. (C) The Lpt pathway. LPS extracted by the $\mathrm{LptB}_{2} \mathrm{CFG}$ complex are transferred to the LptDE complex in the OM through the transenvelope bridge of LptA that spans the entire periplasmic region. The LptDE complex inserts LPS into the outer leaflet of the OM. (D) Phospholipid transport systems. PbgA transports CL in the IM to the OM. The Mla pathway transports PG and PE in the OM to the IM. E. coli has two systems (the Pqi and Yeb pathway) with a central channel capable of mediating phospholipid transport, but it has not been determined yet whether the Pqi and Yeb pathway mediate only retrograde transport of phospholipids or bidirectional migration of phospholipids.

prolipoprotein diacylglyceryl transferase (Lgt), lipoprotein signal peptidase (LspA), and phospholipid/apolipoprotein transacylase (Lnt) [15]. Most mature lipoproteins are then transported to the OM by the LolABCDE pathway [3, 15, 16], and few lipoproteins with a so-called Lol avoidance signal (i.e. an Asp residue at position +2 ) remain in the IM [17].

The LolCD $\mathrm{E}_{2}$ complex belonging to the $\mathrm{ABC}$ transporter superfamily extracts lipoproteins from the IM and transfers extracted lipoproteins to the periplasmic chaperone LolA, resulting in the formation of a soluble lipoprotein-LolA complex (Fig. 1) [16, 18]. This step depends on ATP hydrolysis of the cytoplasmic ATPase LolD [18, 19]. LolE and LolC, which have a significantly structural similarity, seem to play distinct roles, recognition and binding of lipoproteins [20] and the transfer of lipoproteins to LolA [21], respectively.

LolA interacts with lipoproteins through interaction between the large hydrophobic cavity of LolA and the acyl chains of lipoproteins, which shields the highly hydrophobic region of lipoprotein from the hydrophilic periplasm [22].
LolA transports lipoproteins to the OM lipoprotein LolB, which shares remarkably structural similarity with LolA [15]. The acyl chain transfer between LolA and LolB seems to be achieved by the directional mouth-to-mouth delivery driven by an affinity difference between the hydrophobic cavities of LolA and LolB for the acyl chain [21]. Lipoproteins of LolB are released in the OM, but its precise mechanism remains poorly understood [3]. The protruding loop of LolB seems to be important for lipoprotein insertion, as a LolB variant with a point mutation within this loop can receive lipoproteins from LolA, but is not able to mediate the OM insertion of lipoproteins [23]. All lol genes are essential in Escherichia coli [15], and although the lolA and lolD genes are conserved in all proteobacteria, conservation of other genes varies [15]. For example, LolB is absent in $\alpha-, \delta-$, and $\varepsilon$-proteobacteria [3]. A recent study suggests that E.coli may have an alternate transport pathway independent of LolA and LolB proteins. Perhaps species without LolB seem to use a LolAB-independent alternate pathway as the main system for lipoprotein transport. 


\section{OMPs}

OMPs are OM transmembrane proteins with a $\beta$-barrel structure consisting of antiparallel $\beta$-sheets [24]. OMPs synthesized in the cytoplasm are transported to the periplasm by the Sec system. The nascent OMPs in the periplasm are guided by several periplasmic chaperones, such as SurA and Skp, which deliver OMPs to the $\beta$-barrel assembly machinery (BAM) complex in the OM (Fig. 1) [25]. The BAM complex is an insertase machinery consisting of five proteins (BamABCDF). BamA, an OMP itself, has a highly conserved D15 domain forming a 16-strand $\beta$-barrel, which is essential for the insertase activity of the BAM complex [26], and five periplasmic polypeptide transport associated domains (POTRA domains) in the N-terminal region, which function as protein-protein interaction domains [27]. BamA forms a tight complex with four lipoproteins (BamBCDE). Based on structural and functional studies, there are two working models: the assistance model of BamA for spontaneous insertion of OMPs (BamAassisted model) and the conformational change model of OMPs within BamA followed by insertion into the OM via lateral opening of BamA (BamA-budding model) [25], but their precise mechanism remains unclear. Because BamA is itself an OMP, there is a "chicken-or-the-egg" question about BamA assembly. Recent studies suggest that BamB and BamD assist in the early assembly of BamA, and then the BAM complex containing all components may complete the BamA biogenesis [28, 29].

\section{LPS}

LPSs, which are composed of lipid A, core oligosaccharide, and $\mathrm{O}$-antigen polysaccharide chains, are transported by the lipopolysaccharide transport (Lpt) pathway consisting of seven essential proteins (LptABCDEFG) (Fig. 1) [30]. The Lpt pathway is divided into two subassemblies, the nonconventional $\mathrm{ABC}$ transporter $\mathrm{LptB}_{2} \mathrm{CFG}$ located at the IM and LptDE located at the OM. Two sub-complexes are connected by the periplasmic chaperone LptA, which oligomerizes to form a transenvelope bridge that spans the entire periplasmic region from the IM to the OM [31]. LptA interacts with each other in a head-to-tail orientation [32] and their $\mathrm{N}$-terminal and $\mathrm{C}$-terminal regions interact with the C-terminal regions of $\mathrm{LptC}$ in the IM and the $\mathrm{N}$ terminal regions of $\mathrm{LptD}$ in the $\mathrm{OM}$, respectively [33]. Similar to the $\mathrm{LolCD}_{2} \mathrm{E}$ complex, the $\mathrm{LptB}_{2} \mathrm{CFG}$ complex extracts LPS from the outer leaflet of the IM using ATP hydrolysis and transfers it to $\mathrm{LptC}$, an IM protein containing a single N-terminal transmembrane helix and a large soluble periplasmic domain [34]. LptC interacts with
LptB ${ }_{2}$ CFG complex and delivers LPS to LptA [34]. LptA has a highly structural similarity (a so-called Lpt-fold) with the periplasmic domain of $\mathrm{LptC}$ [35] and the Lpt-fold has a hydrophobic pocket for binding to the lipid moiety of LPS [34]. Similar to the transfer of lipoproteins between LolA and LolB [21], the transfer of LPS from LptC to LptA seems to be achieved by the spontaneous delivery driven by an affinity difference between LptC and LptA for the lipid moiety [35]. Although the exact delivery mechanism of LPS to the OM by LptA and the number of LptA present in the transenvelope bridge are not fully determined, several studies show that LptA oligomerization is necessary for the interaction with LPS and the delivery through periplasm $[36,37]$. The LptDE complex, comprising the $\beta$-barrel protein $\mathrm{LptD}$ and the lipoprotein $\mathrm{LptE}$, forms a so-called plug-and-barrel structure with the entire insertion of LptE inserted into the $\beta$-barrel of LptD [38]. The N-terminal periplasmic domain of LptD has an Lpt-fold for interaction with LPS and seems to be involved in the delivery of LPS from LptA to the LptDE complex [30]. Several studies suggest that LPS may laterally pass through the $\beta$-barrel lumen of LptsD and may be directly inserted into the outer leaflet of the OM [39-41]. LptE seems to play various important roles in controlling the correct maturation of the LptD disulfide bonds [42], plugging the too large lumen of LptD [30, 43, 44], and disaggregating LPS during transport through interaction with negative charges of LPS [45].

\section{Phospholipids}

The envelope of E. coli is composed of three major phospholipids, the phophatidylethanolamine (PE, approximately $70 \%$ of the total lipid), the phosphatidylglycerol (PG, approximately 20\%), and cardiolipin (CL, approximately $10 \%$ ) [2]. Unlike other OM components, very little is known about the transport of phospholipids from the IM to the OM. Several systems involved in maintaining OM asymmetry under stress conditions have been reported [2, $46,47]$. The outer leaflet of the OM consists of LPS and the inner leaflet is composed of phospholipids. The unique asymmetry of the OM seems to be important for its barrier function [48]. The phospholipids mislocalized in the outer leaflet of the OM may make a patch in the OM which is permeable to hydrophobic molecules, resulting in sensitivity to detergents and bile salts [48]. Several systems to restore the lipid asymmetry of the OM were identified: the phospholipase PldA degrades phospholipids in the outer leaflet of the OM [49] and the palmitoyltransferase PagP transfers the acyl chain (palmitate) of surface-exposed phospholipids to lipid A of LPS (hepta-acylation of LPS) 
[50]. The maintenance of lipid asymmetry (Mla) pathway mediates retrograde transport of phospholipids mislocalized in the outer leaflet of the OM (Fig. 1) [46]. This pathway comprises the MlaA-OmpC complex in the $\mathrm{OM}$, the periplasmic protein $\mathrm{MlaC}$, and the $\mathrm{MlaB}_{2} \mathrm{E}_{2} \mathrm{DF}_{2}$ complex in the IM [2]. The mla genes are not essential, but their deletion mutants show phenotypes of OM permeability defect and an increased accumulation of phospholipids in the outer leaflet of the OM [46]. MlaA interacts with the OM porin OmpC [51]. The deletion of the ompC gene results in a phenotype similar to the mlaA deletion mutant, suggesting that $\mathrm{OmpC}$ may mediate the extraction of mislocalized phospholipids, although its mechanism has not been determined. E. coli has two additional systems involved in the maintenance of lipid asymmetry, the PqiABC complex and the YebST complex (Fig. 1) [47]. TLC analysis using purified proteins showed that members (MlaD, PqiB, and YebT) of the mammalian cell entry (MCE) protein family bind to phospholipids [47]. The EM structures of three MCE proteins suggest that PqiB and YebT may form a syringe-like architecture and an elongated tube, respectively, which span the entire periplasmic region from the IM to the OM [47]. It has not been determined yet whether PqiABC and YebST mediate only retrograde transport of phospholipids or bidirectional migration of phospholipids. Notably, proteins involved in the bulk transport of phospholipids from the IM to the OM have not been identified yet. Recently, the IM protein PbgA was identified as the CL transporter in Salmonella [52], but it remains to be evaluated whether this protein is a general transporter of CL or is involved in CL transport under stress conditions.

\section{Inhibitors Targeting the OM Assembly Machines}

The development of antimicrobial agents inhibiting the transport of OM components, including lipoproteins, OMPs, LPS, and phospholipids, would provide an entirely new class of antimicrobial agents. We analyzed all studies on the development of inhibitors targeting $\mathrm{OM}$ assembly machines.

\section{Inhibitors of Lipoprotein Transport}

The identification of chemical compounds that inhibit the Lol pathway has been extensively researched (Table 1). The first identified compounds, CCT-00431 and CCT-00432, were found by an inhibition assay of the LolA-dependent release of L10P, an Lpp derivative, from the LolCDE-L10P complex [53]. CCT-00431 and CCT-00432 inhibited the formation of the LolA-L10P complex by $30 \%$ and $60 \%$, respectively [53]. The minimal inhibitory concentrations (MICs) of CCT-00431 and CCT-00432 for E. coli strains were around $16 \mu \mathrm{g} / \mathrm{ml}$, and their MICs for the lpp-deleted mutant increased up to $128 \mu \mathrm{g} / \mathrm{ml}$ [53], suggesting that the target of these compounds is the Lol pathway and that the screening assay is useful to identify inhibitors targeting the Lol pathway. In 2009, a novel chemical compound, MAC13243, targeting the LolA protein was identified through a high-throughput screen for suppressors of growth inhibitory compounds by the high expression of the essential genes [54]. This assay is based on the assumption that the high expression of an essential target of an antimicrobial agent may suppress the growth inhibitory effect by the antimicrobial agent. The accuracy of the assay was proven by the identification of targets of six wellknown antimicrobial agents as high-copy suppressors of lethality [54]. For example, the $f_{0} l C$ gene involved in the folate biosynthesis was found to be a suppressor of chemical lethality of sulfamethoxazole, an antimicrobial agent that inhibits the folate synthesis. This screen assay identified a novel inhibitor of LolA, MAC13243. MAC13243 inhibited the function of LolA through direct interaction and the dissociation constant $\left(K_{\mathrm{D}}\right)$ between MAC13243 and LolA was $7.5 \mu \mathrm{M}$ [54]. The MICs of MAC13243 for E. coli and $P$. aeruginosa were 16 and $8 \mu \mathrm{g} / \mathrm{ml}$, respectively, and the MIC of MAC13243 was not affected by the overexpression of the $a c r B$ gene encoding an efflux pump [54]. Because the MICs of MAC13243 for Gram-positive bacteria, such as Bacillus subtilis and Staphylococcus aureus, were significantly higher $(>256 \mu \mathrm{g} / \mathrm{ml}$ ) than those of Gram-negative bacteria, MAC13243 is an antimicrobial lead compound against Gram-negative bacteria selectively. In an aqueous solution, MAC13243 can be degraded into 3,4-dimethoxyphenethylamine and S-(4-chlorobenzyl)isothiourea [55]. S-(4-chlorobenzyl) isothiourea is an analog of A22 [S-(3,4-dichlorobenzyl) isothiourea], a well-known molecule inhibiting the actinlike bacterial cell shape determining protein MreB [56]. Notably, like MAC13243, the antimicrobial activities of $S$ (4-chlorobenzyl)isothiourea and A22 were suppressed by LolA overproduction, while their activities were sensitized by LolA depletion [55]. These results suggest that S-(4chlorobenzyl)isothiourea and A22 have a mode of action similar to MAC13243. This assumption was confirmed by the interaction of these compounds with LolA. Therefore, S-(4-chlorobenzyl)isothiourea and A22 seem to have a similar mode of action that includes inhibition of LolA as well as MreB.

Several compounds inhibiting the $\mathrm{LolCD}_{2} \mathrm{E}$ complex were identified [57-59]. A pyrazole-containing compound 
Table 1. Antimicrobial inhibitors targeting the OM assembly machines.

\begin{tabular}{|c|c|c|c|c|c|c|}
\hline $\begin{array}{l}\text { Assembly } \\
\text { machine }\end{array}$ & Inhibitor & $\begin{array}{c}\text { Cellular } \\
\text { target }\end{array}$ & $\mathrm{IC}_{50}^{\mathrm{a}}$ & $\operatorname{MIC}(\mu \mathrm{g} / \mathrm{ml})$ & $\begin{array}{l}\text { MIC in the } \\
\text { resistant mutant }\end{array}$ & Reference \\
\hline \multirow[t]{7}{*}{$\begin{array}{l}\text { The Lol } \\
\text { pathway }\end{array}$} & $\begin{array}{l}\text { CCT-00431 and CCT- } \\
00432\end{array}$ & LolA & N.D. ${ }^{\mathrm{b}}$ & $\begin{array}{l}16 \text { (E. coli } \mathrm{NIHJ} \text { JC-2) } \\
8(\text { E. coli } \mathrm{M} 101)\end{array}$ & $\begin{array}{l}8 \text { (Parent) } \\
32 \text { or } 128(\Delta l p p)\end{array}$ & [53] \\
\hline & MAC13243 & LolA & N.D. & $\begin{array}{l}16 \text { (E. coli ATCC25922) } \\
4 \text { (Pseudomonas aeruginosa PAO1) }\end{array}$ & N.D. & [54] \\
\hline & $\begin{array}{l}\text { S-(4-chlorobenzyl)iso- } \\
\text { thiourea and S-(3,4- } \\
\text { dichlorobenzyl)iso- } \\
\text { thiourea (A22) }\end{array}$ & LolA & $\begin{array}{l}\mathrm{IC}_{50}=150 \mu \mathrm{M}[S \text {-(4-chlo- } \\
\text { robenzyl)isothiourea] } \\
\mathrm{IC}_{50}=200 \mu \mathrm{M}(\mathrm{A} 22)\end{array}$ & 2 (E. coli MG1655) & N.D. & [55] \\
\hline & $\begin{array}{l}\text { Pyrazole-containing } \\
\text { compound }\end{array}$ & $\begin{array}{l}\text { LolC } \\
\text { and } \\
\text { LolE }\end{array}$ & N.D. & $\begin{array}{l}8(\text { E. coli ATCC25922) } \\
0.125 \text { (E. coli ATCC25922 } \Delta \text { tolC) } \\
32(\text { Haemophilus influenza ATCC49247) } \\
>64 \text { (Pseudomonas aeruginosa PAO1) }\end{array}$ & $\begin{array}{l}0.125 \text { (Parent) } \\
>128[\operatorname{LolC}(\mathrm{G} 254 \mathrm{~V})] \\
>128[\mathrm{LolE}(\mathrm{G} 195 \mathrm{~S})] \\
>128[\mathrm{LolE}(\mathrm{P} 365 \mathrm{C})] \\
>128[\mathrm{LolE}(\mathrm{P} 367 \mathrm{Y})]\end{array}$ & [58] \\
\hline & $\begin{array}{l}\text { Pyridineimidazole-con- } \\
\text { taining compound } 1\end{array}$ & $\begin{array}{l}\text { LolC } \\
\text { and } \\
\text { LolE }\end{array}$ & N.D. & $\begin{array}{l}32 \text { (E. coli ATCC25922) } \\
0.25 \text { (E. coli ATCC25922 } \Delta \text { tolC) } \\
2 \text { (Haemophilus influenza ATCC49247) } \\
>64 \text { (Pseudomonas aeruginosa PAO1) }\end{array}$ & $\begin{array}{l}0.125 \text { (Parent) } \\
>64[\operatorname{LolC}(\mathrm{N} 265 \mathrm{~K})] \\
>64[\mathrm{LolE}(\mathrm{I} 59 \mathrm{~N})] \\
64[\mathrm{LolE}(\mathrm{P} 372 \mathrm{~L})] \\
>64[\operatorname{LolE}(\mathrm{L} 371 \mathrm{P})]\end{array}$ & [57] \\
\hline & $\begin{array}{l}\text { Pyridineimidazole-con- } \\
\text { taining compound } 2\end{array}$ & $\begin{array}{l}\text { LolC } \\
\text { and } \\
\text { LolE }\end{array}$ & N.D. & $\begin{array}{l}4 \text { (E. coli ATCC25922) } \\
<0.06 \text { (E. coli ATCC25922 } \Delta \text { tolC) } \\
0.25 \text { (Haemophilus influenza ATCC49247) } \\
>64 \text { (Pseudomonas aeruginosa PAO1) }\end{array}$ & $\begin{array}{l}<0.06(\text { Parent }) \\
>64[\operatorname{LolC}(\mathrm{N} 265 \mathrm{~K})] \\
>64[\mathrm{LolE}(\mathrm{I} 59 \mathrm{~N})] \\
8[\operatorname{LolE}(\mathrm{P} 372 \mathrm{~L})] \\
>64[\mathrm{LolE}(\mathrm{L} 371 \mathrm{P})]\end{array}$ & [57] \\
\hline & $\begin{array}{l}\text { Pyrrolopyrimidinedione } \\
\text { compound G507 }\end{array}$ & LolCDE & N.D. & $\begin{array}{l}>64 \text { (E. coli MG1655) } \\
0.5 \text { (E. coli MG1655 } \Delta \text { tolC) } \\
1 \text { (E. coli MG1655 imp } 4213) \\
16 \text { (TQ/he MIC of G0793 against E. coli } \\
\text { MG1655) }\end{array}$ & N.D. & [59] \\
\hline \multirow[t]{5}{*}{$\begin{array}{l}\text { The Lpt } \\
\text { pathway }\end{array}$} & Compound 1 and 2 & LptB & $\begin{array}{l}\mathrm{IC}_{50}=25 \mu \mathrm{M} \\
\text { (compound } 1 \text { ) } \\
\mathrm{IC}_{50}=17 \mu \mathrm{M} \\
\text { (compound 2) }\end{array}$ & N.D. & N.D. & [63] \\
\hline & $\begin{array}{l}\text { 4-Phenylpyrrolocarba- } \\
\text { zole derivatives, } 1 \mathrm{a} \text { and } \\
1 \mathrm{~b}\end{array}$ & LptB & $\mathrm{IC}_{50}=119 \mu \mathrm{M}$ & $\begin{array}{l}>100(\text { E. coli } \mathrm{MC} 4100) \\
25(\text { E. coli } \mathrm{NR} 698)\end{array}$ & N.D. & [64] \\
\hline & $\begin{array}{l}\text { Peptidomimetic } \\
\text { compound L27-11 }\end{array}$ & LptD & N.D. & $\begin{array}{l}0.01 \text { (Pseudomonas aeruginosa } \\
\text { ATCC27853) } \\
0.004 \text { (Pseudomonas aeruginosa PAO1) }\end{array}$ & $\begin{array}{l}0.06 \text { (Parent) } \\
>64 \text { (Duplication of } \\
\text { residues 210-215 of LptD) }\end{array}$ & [68] \\
\hline & $\begin{array}{l}\beta \text {-hairpin-shaped } \\
\text { peptidomimetic } \\
\text { compound LB-01 }\end{array}$ & LptD & N.D. & $\begin{array}{l}0.008 \text { (Pseudomonas aeruginosa } \\
\text { ATCC27853) } \\
0.015 \text { (Pseudomonas aeruginosa PAO1) }\end{array}$ & N.D. & [71] \\
\hline & $\begin{array}{l}\beta \text {-hairpin-shaped } \\
\text { peptidomimetic } \\
\text { compound Dab4NMe }\end{array}$ & LptD & N.D. & $\begin{array}{l}0.005 \text { (Pseudomonas aeruginosa } \\
\text { ATCC27853) } \\
0.009 \text { (Pseudomonas aeruginosa PAO1) }\end{array}$ & N.D. & [71] \\
\hline $\begin{array}{l}\text { The BAM } \\
\text { pathway }\end{array}$ & $\begin{array}{l}\beta \text {-hairpin macrocyclic pep- } \\
\text { tide JB-95 }\end{array}$ & $\begin{array}{l}\text { BamA } \\
\text { and } \\
\text { LptD }\end{array}$ & N.D. & $\begin{array}{l}0.25 \text { (E. coli ATCC25922) } \\
1 \text { (Acinetobacter baumannii ATCC17978) } \\
4 \text { (Pseudomonas aeruginosa } \text { PAO1) } \\
2 \text { (Staphylococcus aureus ATCC29213) }\end{array}$ & N.D. & [73] \\
\hline
\end{tabular}

${ }^{a}$ The half maximal inhibitory concentration.

${ }^{\mathrm{b}}$ Not determined. 
was found by a high-throughput screen using an AmpC reporter assay [58]. The $\operatorname{ampC} \beta$-lactamase gene is an inducible gene of Citrobacter freundii which can be used as a marker of inhibition of cell wall biosynthesis [60]. To find novel compounds that inhibit cell wall biosynthesis, a high-throughput phenotypic screening using the $C$. freundii AmpC reporter assay was performed [58]. A pyrazolecontaining compound with an MIC of $8 \mu \mathrm{g} / \mathrm{ml}$ for E. coli was identified as an inhibitor of both LolC and LolE. Mutations in either lolC or lolE cause significantly large shifts in the MIC of this compound ( $>128 \mu \mathrm{g} / \mathrm{ml})$, whereas the MICs of other antibiotics were not changed [58], suggesting that this compound may inhibit LolC and LolE activities. A spheroplast release assay showed that the pyrazole-containing compound actually inhibits Lpp release from spheroplasts to LolA. Two pyridineimidazolecontaining compounds (compound 1 and 2) were also identified as inhibitors of LolC and LolE through a highthroughput screen for a compound that inhibits the growth of a permeabilized E. coli strain [57]. The screen identified two compounds that inhibit Lpp release from spheroplasts to LolA and the resistance against these two compounds was found in bacterial cells with mutations in the lolC or lolE gene [57]. Compound 2, a close analog of compound 1, showed greater antimicrobial activity: the MIC of compound 2 against E. coli and Haemophilus influenzae were 8 -fold lower than compound 1 [57]. Recently, a novel inhibitor G0507 of the LolCDE complex was identified by a phenotypic screen of $E$. coli growth inhibition and additional selection of compounds inducing the extracytoplasmic $\sigma^{\mathrm{E}}$ stress response, which is shown to be activated by $\mathrm{OM}$ biogenesis defects $[61,62]$. The pyrrolopyrimidinedionecontaining compound G0507 interacted with the LolCDE complex and stimulated its ATPase activity [59]. Fullyprocessed Lpp were accumulated in the IM of E. coli cells, but not in the OM, after treatment with this compound. These results suggest that the LolCDE complex is a molecular target of G0507. Notably, the Q258K mutation of LolC did not affect the interaction between G0507 and the LolCDE complex, but abolished stimulation of ATPase activity by G0507, and cells with this mutation were resistant to G0507 [59]. These results indicate that the stimulation of ATPase activity is important for the mode of action of G0507. The MIC of G0507 against E. coli MG1655 is $>64 \mu \mathrm{g} / \mathrm{ml}$, but the MIC of its derivative G0793 is $16 \mu \mathrm{g} / \mathrm{ml}$ [59].

\section{Inhibitors of LPS Transport}

Chemicals inhibiting the ATPase activity of the ATPase component $\mathrm{LptB}$ of the $\mathrm{LptB}_{2} \mathrm{CFG}$ complex were screened by a continuous assay that couples ATP hydrolysis to NADH oxidation [63]. Two compounds, 1 and 2, that have different structural classes, inhibited the ATPase activity of LptB with an $\mathrm{IC}_{50}$ of 25 and $17 \mu \mathrm{M}$, respectively [63]. The value of the MICs of these compounds was not determined. In 2013, other inhibitors of LptB were identified by the same biochemical assay, the continuous assay coupling ATP hydrolysis to NADH oxidation [64]. A compound 1a, a 4-phenylpyrrolocarbazole derivative that had previously been known as a potent inhibitor of a eukaryotic kinase Wee1, which regulates mitosis entry [65], was identified as an inhibitor of LptA [64]. Several derivatives of 4phenylpyrrolocarbazole were additionally tested for inhibition of the ATPase activity of LptB. Compounds 1a and $1 \mathrm{~b}$ showed a weak antimicrobial activity (MIC of $>100 \mu \mathrm{g} / \mathrm{ml}$ ) against the E. coli strain MC4100, but MICs against the leaky E. coli strain NR698 were decreased (25 $\mu \mathrm{g} / \mathrm{ml}$ in compound $1 \mathrm{a}$ and $12.5 \mu \mathrm{g} / \mathrm{ml}$ in compound 1b) [64]. Notably, the $\mathrm{IC}_{50}$ of compound $1 \mathrm{~b}$ was 6-fold lower against LptB alone $(19.6 \mu \mathrm{M})$ than against the $\mathrm{LptB}_{2} \mathrm{FGC}$ complex $(119 \mu \mathrm{M})$, suggesting that compound $1 \mathrm{~b}$ is more potent against $\mathrm{LptB}$ alone than the $\mathrm{LptB}_{2} \mathrm{FGC}$ complex.

Several $\beta$-hairpin-shaped peptidomimetics (small proteinlike chains designed to mimic a peptide) targeting the $\beta$ barrel OM protein $\mathrm{LptD}$ were developed by optimization of peptidomimetics based on the antimicrobial peptide protegrin I (PG-I) [66]. PG-I is a broad-spectrum antimicrobial peptide against Gram-negative and Gram-positive bacteria [67], but optimized peptidomimetics, L26-19 and L27-11, display a narrow-spectrum antimicrobial effect only against P. aeruginosa and other Pseudomonas spp., but not other Gram-negative and Gram-positive bacteria [68]. The MICs of L27-11 against P. aeruginosa ATCC27853 and PAO1 were 0.01 and 0.004, respectively, but all MICs against other strains, including Gram-negative bacteria (A. baumannii, K. pneumoniae, and E.coli) and Gram-positive bacteria (Enterococcus faecalis and S. aureus), were $>64 \mu \mathrm{g} / \mathrm{ml}$ [68]. L26-19 displayed a similar antimicrobial activity. L26-19 and L27-11 displayed no cellular lytic activity but exhibited internal accumulation of membrane-like materials in cells and impairment of the $\mathrm{OM}$ integrity. A mutation in the lptD gene increased the MIC of L26-19 against $P$. aeruginosa PAO1 up to $>64 \mu \mathrm{g} / \mathrm{ml}$, and the interaction between L27-11 and LptD was confirmed by photoaffinity labeling analysis [68]. A recent study showed that $\mathrm{L} 27-11$ interacts with the periplasmic domain of $\mathrm{LptD}$ and its $K_{\mathrm{D}}$ is approximately $13 \mathrm{nM}$ [69]. These results indicate that LptD is a cellular target of these peptidomimetics. An alanine scan experiment 
to examine the critical residue for antimicrobial activity of each side chain in L27-11 showed that Trp2 and Trp8 residues located on the opposite face of each side chain are critical [70]. A novel modified derivative of L27-11, called LB-01, with MICs of 0.008 and $0.015 \mu \mathrm{g} / \mathrm{ml}$ against $P$. aeuruginosa ATCC27853 and PAO1, respectively, was developed [70,71]. An $N$-methyl scan experiment using $\mathrm{N}$-methylation of each peptide bond showed that residues on both sides of LB-01 that do not participate in the intramolecular hydrogen bonding may play an important role in hydrogen-bonding interactions with LptD [71]. Additionally, these experiments revealed that several derivatives with $\mathrm{N}$-methylation have more potent antimicrobial activity than LB-01. For example, a Dab4NMe analog of LB-01 displayed MICs of 0.005 and $0.009 \mu \mathrm{g} / \mathrm{ml}$ against $P$. aeuruginosa ATCC27853 and PAO1, respectively [71]. These results show that there is a novel avenue for optimization of peptidomimetics. An L27-11- closely-related clinical candidate Murepavadin (also called POL7080) developed by Polyphor AG has successfully completed phase-II clinical trials (clinical trials identifier NCT02096328) against pseudomonas lung infections [72], suggesting that proteins involved in the LPS transport pathway can be a potential target of antimicrobial agents.

\section{Inhibitors of OMP Transport}

One study investigated an inhibitor that targets the BAM complex. Similar to L27-11, a $\beta$-hairpin macrocyclic peptidomimetic JB-95 was identified as an inhibitor of $\beta$-barrel OM proteins BamA and LptD [73]. JB-95 induced no cellular lytic activity like L27-11, but selectively disrupted the OM integrity, but not the IM, and induced rapid depletion of $\beta$-barrel OM proteins [73]. Photolabeling experiments revealed the interaction of JB-96 with BamA and LptD. The MICs of JB-95 against E. coli ATCC25922, A. baumannii ATCC17978, P. aeruginosa ATCC27853, and S. aureus ATCC29213 were $0.25,1,4$, and $2 \mu \mathrm{g} / \mathrm{ml}$, respectively [73]. These results propose a novel avenue for developing antimicrobial agents targeting $\beta$-barrel proteins of the OM.

Upon the revelation of a more complete picture of the transport system of OM components, the possibility of developing antimicrobial agents targeting OM transport machines was examined. The most successful case is Murepavadin, an L27-11-based peptidomimetic inhibitor of LptD, which has successfully completed phase-II clinical trials [72]. Because several additional optimization procedures of L27-11 have been suggested [70, 71], there is the possibility of developing more potent antimicrobial agents.
Although there have been various attempts at developing new antibiotics targeting the Lol system, an inhibitor with an MIC in the nanomolar range has not yet been developed. The high-throughput screen of inhibitors based on peptidomimetics may be useful for the development of inhibitors of the Lol system. Because the transport system of phospholipids from the IM to the OM remains undetermined, extensive studies are required in this field. The phospholipid transport system has potential to be a novel target for the development of new antimicrobial agents against Gram-negative bacteria.

\section{Acknowledgements}

This work was supported by research grants from the Advanced Biomass R\&D Center (ABC) of the Global Frontier Project funded by the Ministry of Science, ICT and Future Planning (ABC-2015M3A6A2065700), and the Bio \& Medical Technology Development Program of the NRF funded by the Korean government, MSIT (NRF-2017M3A9E4078017).

\section{Conflict of Interest}

The authors have no financial conflicts of interest to declare.

\section{References}

1. Patel DS, Qi Y, Im W. 2017. Modeling and simulation of bacterial outer membranes and interactions with membrane proteins. Curr. Opin. Struct. Biol. 43: 131-140.

2. May KL, Silhavy TJ. 2017. Making a membrane on the other side of the wall. Biochim. Biophys. Acta Mol. Cell Biol. Lipids 1862: 1386-1393.

3. Grabowicz M. 2018. Lipoprotein transport: greasing the machines of outer membrane biogenesis: re-examining lipoprotein transport mechanisms among diverse Gramnegative bacteria while exploring new discoveries and questions. BioEssays 40: e1700187

4. Typas A, Banzhaf M, van den Berg van Saparoea B, Verheul J, Biboy J, Nichols RJ, et al. 2010. Regulation of peptidoglycan synthesis by outer-membrane proteins. Cell 143: 1097-1109.

5. Paradis-Bleau C, Markovski M, Uehara T, Lupoli TJ, Walker S, Kahne DE, et al. 2010. Lipoprotein cofactors located in the outer membrane activate bacterial cell wall polymerases. Cell 143: 1110-1120.

6. Liu R, Ochman H. 2007. Stepwise formation of the bacterial flagellar system. Proc. Natl. Acad. Sci. USA 104: 7116-7121.

7. Hospenthal MK, Costa TRD, Waksman G. 2017. A comprehensive guide to pilus biogenesis in Gram-negative bacteria. Nat. Rev. Microbiol. 15: 365-379. 
8. Durand E, Nguyen VS, Zoued A, Logger L, Pehau-Arnaudet G, Aschtgen MS, et al. 2015. Biogenesis and structure of a type VI secretion membrane core complex. Nature 523: 555-560.

9. Dong C, Beis K, Nesper J, Brunkan-Lamontagne AL, Clarke BR, Whitfield C, et al. 2006. Wza the translocon for E.coli capsular polysaccharides defines a new class of membrane protein. Nature 444: 226-229.

10. Zeth K, Thein M. 2010. Porins in prokaryotes and eukaryotes: common themes and variations. Biochem. J. 431: 13-22.

11. Lee CR, Lee JH, Park M, Park KS, Bae IK, Kim YB et al. 2017. Biology of Acinetobacter baumannii: pathogenesis, antibiotic resistance mechanisms, and prospective treatment options. Front. Cell. Infect. Microbiol. 7: 55.

12. O'Shea R, Moser HE. 2008. Physicochemical properties of antibacterial compounds: implications for drug discovery. $J$. Med. Chem. 51: 2871-2878.

13. Lee CR, Cho IH, Jeong BC, Lee SH. 2013. Strategies to minimize antibiotic resistance. Int. J. Environ. Res. Public Health 10: 4274-4305.

14. Lee CR, Lee JH, Park KS, Jeon JH, Kim YB, Cha CJ, et al. 2017. Antimicrobial resistance of hypervirulent Klebsiella pneumoniae: epidemiology, hypervirulence-associated determinants, and resistance mechanisms. Front. Cell. Infect. Microbiol. 7: 483.

15. Konovalova A, Silhavy TJ. 2015. Outer membrane lipoprotein biogenesis: Lol is not the end. Philos. Trans. R. Soc. Lond. B. Biol. Sci. 370: 1679.

16. Narita SI, Tokuda H. 2017. Bacterial lipoproteins; biogenesis, sorting and quality control. Biochim. Biophys. Acta 1862: 1414-1423.

17. Yamaguchi K, Yu F, Inouye M. 1988. A single amino acid determinant of the membrane localization of lipoproteins in E. coli. Cell 53: 423-432

18. Yakushi T, Masuda $K$, Narita S, Matsuyama S, Tokuda H. 2000. A new $A B C$ transporter mediating the detachment of lipid-modified proteins from membranes. Nat. Cell. Biol. 2: 212-218.

19. Yakushi T, Yokota N, Matsuyama S, Tokuda H. 1998. LolAdependent release of a lipid-modified protein from the inner membrane of Escherichia coli requires nucleoside triphosphate. J. Biol. Chem. 273: 32576-32581.

20. Mizutani M, Mukaiyama K, Xiao J, Mori M, Satou R, Narita S, et al. 2013. Functional differentiation of structurally similar membrane subunits of the $\mathrm{ABC}$ transporter LolCDE complex. FEBS Lett. 587: 23-29.

21. Okuda S, Tokuda H. 2009. Model of mouth-to-mouth transfer of bacterial lipoproteins through inner membrane LolC, periplasmic LolA, and outer membrane LolB. Proc. Natl. Acad. Sci. USA 106: 5877-5882.

22. Takeda K, Miyatake H, Yokota N, Matsuyama S, Tokuda H, Miki K. 2003. Crystal structures of bacterial lipoprotein localization factors, LolA and LolB. EMBO J. 22: 3199-3209.

23. Hayashi Y, Tsurumizu R, Tsukahara J, Takeda K, Narita S,
Mori M, et al. 2014. Roles of the protruding loop of factor B essential for the localization of lipoproteins (LolB) in the anchoring of bacterial triacylated proteins to the outer membrane. J. Biol. Chem. 289: 10530-10539.

24. Walther DM, Rapaport D, Tommassen J. 2009. Biogenesis of $\beta$-barrel membrane proteins in bacteria and eukaryotes: evolutionary conservation and divergence. Cell. Mol. Life Sci. 66: 2789-2804.

25. Noinaj N, Rollauer SE, Buchanan SK. 2015. The $\beta$-barrel membrane protein insertase machinery from Gram-negative bacteria. Curr. Opin. Struct. Biol. 31: 35-42.

26. Voulhoux R, Bos MP, Geurtsen J, Mols M, Tommassen J. 2003. Role of a highly conserved bacterial protein in outer membrane protein assembly. Science 299: 262-265.

27. Kim S, Malinverni JC, Sliz P, Silhavy TJ, Harrison SC, Kahne D. 2007. Structure and function of an essential component of the outer membrane protein assembly machine. Science 317: 961-964.

28. Misra R, Stikeleather R, Gabriele R. 2015. In vivo roles of BamA, BamB and BamD in the biogenesis of BamA, a core protein of the $\beta$-barrel assembly machine of Escherichia coli. J. Mol. Biol. 427: 1061-1074.

29. Hagan CL, Westwood DB, Kahne D. 2013. Bam lipoproteins assemble BamA in vitro. Biochemistry 52: 6108-6113.

30. Sperandeo P, Martorana AM, Polissi A. 2017. The lipopolysaccharide transport (Lpt) machinery: a nonconventional transporter for lipopolysaccharide assembly at the outer membrane of Gram-negative bacteria. J. Biol. Chem. 292: 17981-17990.

31. Suits MD, Sperandeo P, Deho G, Polissi A, Jia Z. 2008. Novel structure of the conserved gram-negative lipopolysaccharide transport protein $\mathrm{A}$ and mutagenesis analysis. J. Mol. Biol. 380: 476-488.

32. Merten JA, Schultz KM, Klug CS. 2012. Concentrationdependent oligomerization and oligomeric arrangement of LptA. Protein Sci. 21: 211-218.

33. Freinkman E, Okuda S, Ruiz N, Kahne D. 2012. Regulated assembly of the transenvelope protein complex required for lipopolysaccharide export. Biochemistry 51: 4800-4806.

34. Okuda S, Freinkman E, Kahne D. 2012. Cytoplasmic ATP hydrolysis powers transport of lipopolysaccharide across the periplasm in E. coli. Science 338: 1214-1217.

35. Tran AX, Dong C, Whitfield C. 2010. Structure and functional analysis of $\mathrm{LptC}$, a conserved membrane protein involved in the lipopolysaccharide export pathway in Escherichia coli. J. Biol. Chem. 285: 33529-33539.

36. Laguri C, Sperandeo P, Pounot K, Ayala I, Silipo A, Bougault CM, et al. 2017. Interaction of lipopolysaccharides at intermolecular sites of the periplasmic Lpt transport assembly. Sci. Rep. 7: 9715.

37. Schultz KM, Lundquist TJ, Klug CS. 2017. Lipopolysaccharide binding to the periplasmic protein LptA. Protein Sci. 26: 1517-1523. 
38. Freinkman E, Chng SS, Kahne D. 2011. The complex that inserts lipopolysaccharide into the bacterial outer membrane forms a two-protein plug-and-barrel. Proc. Natl. Acad. Sci. USA 108: 2486-2491.

39. Gu Y, Stansfeld PJ, Zeng Y, Dong H, Wang W, Dong C. 2015. Lipopolysaccharide is inserted into the outer membrane through an intramembrane hole, a lumen gate, and the lateral opening of LptD. Structure 23: 496-504.

40. Li X, Gu Y, Dong H, Wang W, Dong C. 2015. Trapped lipopolysaccharide and LptD intermediates reveal lipopolysaccharide translocation steps across the Escherichia coli outer membrane. Sci. Rep. 5: 11883.

41. Sperandeo P, Martorana AM, Polissi A. 2017. Lipopolysaccharide biogenesis and transport at the outer membrane of Gram-negative bacteria. Biochim. Biophys. Acta 1862: 14511460 .

42. Chng SS, Xue M, Garner RA, Kadokura H, Boyd D, Beckwith J, et al. 2012. Disulfide rearrangement triggered by translocon assembly controls lipopolysaccharide export. Science 337: 1665-1668.

43. Chng SS, Ruiz N, Chimalakonda G, Silhavy TJ, Kahne D. 2010. Characterization of the two-protein complex in Escherichia coli responsible for lipopolysaccharide assembly at the outer membrane. Proc. Natl. Acad. Sci. USA 107: 53635368 .

44. Chimalakonda G, Ruiz N, Chng SS, Garner RA, Kahne D, Silhavy TJ. 2011. Lipoprotein $\mathrm{LptE}$ is required for the assembly of LptD by the beta-barrel assembly machine in the outer membrane of Escherichia coli. Proc. Natl. Acad. Sci. USA 108: 2492-2497.

45. Malojcic G, Andres D, Grabowicz M, George AH, Ruiz N, Silhavy TJ, et al. 2014. LptE binds to and alters the physical state of LPS to catalyze its assembly at the cell surface. Proc. Natl. Acad. Sci. USA 111: 9467-9472.

46. Malinverni JC, Silhavy TJ. 2009. An ABC transport system that maintains lipid asymmetry in the gram-negative outer membrane. Proc. Natl. Acad. Sci. USA 106: 8009-8014.

47. Ekiert DC, Bhabha G, Isom GL, Greenan G, Ovchinnikov S, Henderson IR, et al. 2017. Architectures of lipid transport systems for the bacterial outer membrane. Cell 169: 273-285 e217.

48. Ruiz N, Wu T, Kahne D, Silhavy TJ. 2006. Probing the barrier function of the outer membrane with chemical conditionality. ACS Chem. Biol. 1: 385-395.

49. Dekker N. 2000. Outer-membrane phospholipase A: known structure, unknown biological function. Mol. Microbiol. 35: 711-717.

50. Bishop RE, Gibbons HS, Guina T, Trent MS, Miller SI, Raetz CR. 2000. Transfer of palmitate from phospholipids to lipid $A$ in outer membranes of gram-negative bacteria. EMBO J. 19: 5071-5080.

51. Chong ZS, Woo WF, Chng SS. 2015. Osmoporin OmpC forms a complex with MlaA to maintain outer membrane lipid asymmetry in Escherichia coli. Mol. Microbiol. 98: 11331146.

52. Dalebroux ZD, Edrozo MB, Pfuetzner RA, Ressl S, Kulasekara BR, Blanc MP et al. 2015. Delivery of cardiolipins to the Salmonella outer membrane is necessary for survival within host tissues and virulence. Cell. Host Microbe 17: 441-451.

53. Ito H, Ura A, Oyamada Y, Yoshida H, Yamagishi J, Narita S et al. 2007. A new screening method to identify inhibitors of the Lol (localization of lipoproteins) system, a novel antibacterial target. Microbiol. Immunol. 51: 263-270.

54. Pathania R, Zlitni S, Barker C, Das R, Gerritsma DA, Lebert J, et al. 2009. Chemical genomics in Escherichia coli identifies an inhibitor of bacterial lipoprotein targeting. Nat. Chem. Biol. 5: 849-856.

55. Barker CA, Allison SE, Zlitni S, Nguyen ND, Das R, Melacini G, et al. 2013. Degradation of MAC13243 and studies of the interaction of resulting thiourea compounds with the lipoprotein targeting chaperone LolA. Bioorg. Med. Chem. Lett. 23: 2426-2431.

56. Iwai N, Nagai K, Wachi M. 2002. Novel S-benzylisothiourea compound that induces spherical cells in Escherichia coli probably by acting on a rod-shape-determining protein(s) other than penicillin-binding protein 2. Biosci. Biotechnol. Biochem. 66: 2658-2662.

57. McLeod SM, Fleming PR, MacCormack K, McLaughlin RE, Whiteaker JD, Narita S, et al. 2015. Small-molecule inhibitors of gram-negative lipoprotein trafficking discovered by phenotypic screening. J. Bacteriol. 197: 1075-1082.

58. Nayar AS, Dougherty TJ, Ferguson KE, Granger BA, McWilliams L, Stacey C, et al. 2015. Novel antibacterial targets and compounds revealed by a high-throughput cell wall reporter assay. J. Bacteriol. 197: 1726-1734.

59. Nickerson NN, Jao CC, Xu Y, Quinn J, Skippington E, Alexander MK, et al. 2018. A novel inhibitor of the LolCDE $A B C$ transporter essential for lipoprotein trafficking in Gram-negative bacteria. Antimicrob. Agents Chemother. 62: 4.

60. Sun D, Cohen S, Mani N, Murphy C, Rothstein DM. 2002. A pathway-specific cell based screening system to detect bacterial cell wall inhibitors. J. Antibiot. (Tokyo) 55: 279-287.

61. Tam C, Missiakas D. 2005. Changes in lipopolysaccharide structure induce the $\sigma^{\mathrm{E}}$-dependent response of Escherichia coli. Mol. Microbiol. 55: 1403-1412.

62. Lima S, Guo MS, Chaba R, Gross CA, Sauer RT. 2013. Dual molecular signals mediate the bacterial response to outermembrane stress. Science 340: 837-841.

63. Gronenberg LS, Kahne D. 2010. Development of an activity assay for discovery of inhibitors of lipopolysaccharide transport. J. Am. Chem. Soc. 132: 2518-2519.

64. Sherman DJ, Okuda S, Denny WA, Kahne D. 2013. Validation of inhibitors of an $\mathrm{ABC}$ transporter required to transport lipopolysaccharide to the cell surface in Escherichia coli. Bioorg. Med. Chem. 21: 4846-4851. 
65. Parker LL, Piwnica-Worms H. 1992. Inactivation of the p34cdc2-cyclin B complex by the human WEE1 tyrosine kinase. Science 257: 1955-1957.

66. Kokryakov VN, Harwig SS, Panyutich EA, Shevchenko AA, Aleshina GM, Shamova OV, et al. 1993. Protegrins: leukocyte antimicrobial peptides that combine features of corticostatic defensins and tachyplesins. FEBS Lett. 327: 231-236.

67. Steinberg DA, Hurst MA, Fujii CA, Kung AH, Ho JF, Cheng FC, et al. 1997. Protegrin-1: a broad-spectrum, rapidly microbicidal peptide with in vivo activity. Antimicrob. Agents Chemother. 41: 1738-1742.

68. Srinivas N, Jetter P, Ueberbacher BJ, Werneburg M, Zerbe K, Steinmann J, et al. 2010. Peptidomimetic antibiotics target outer-membrane biogenesis in Pseudomonas aeruginosa. Science 327: 1010-1013.

69. Andolina G, Bencze LC, Zerbe K, Muller M, Steinmann J, Kocherla $\mathrm{H}$, et al. 2018. A peptidomimetic antibiotic interacts with the periplasmic domain of $\mathrm{LptD}$ from Pseudomonas aeruginosa. ACS Chem. Biol. 13: 666-675.

70. Schmidt J, Patora-Komisarska K, Moehle K, Obrecht D, Robinson JA. 2013. Structural studies of $\beta$-hairpin peptidomimetic antibiotics that target LptD in Pseudomonas sp. Bioorg. Med. Chem. 21: 5806-5810.

71. Vetterli SU, Moehle K, Robinson JA. 2016. Synthesis and antimicrobial activity against Pseudomonas aeruginosa of macrocyclic $\beta$-hairpin peptidomimetic antibiotics containing $\mathrm{N}$-methylated amino acids. Bioorg. Med. Chem. 24: 6332-6339.

72. Zerbe K, Moehle K, Robinson JA. 2017. Protein epitope mimetics: from new antibiotics to supramolecular synthetic vaccines. Acc. Chem. Res. 50: 1323-1331.

73. Urfer M, Bogdanovic J, Lo Monte F, Moehle K, Zerbe K, Omasits U, et al. 2016. A peptidomimetic antibiotic targets outer membrane proteins and disrupts selectively the outer membrane in Escherichia coli. J. Biol. Chem. 291: 1921-1932. 